\title{
Comparison between Post-tonsillectomy Bleeding of Three Different Techniques in Children
}

\section{Abdullah Alzuwayed ${ }^{*}$ and Mohammad Qattan}

King Saud bin Abdulaziz University, Riyadh 14611, Saudi Arabia

*Corresponding author: Abdullah Alzuwayed, ENT Teaching Assistant, King Saud bin Abdulaziz University, Riyadh 14611 , Saudi Arabia, Tel: 966 11 429 9999; E-mail: dr.alzuwayed@gmail.com

Received date: December 1, 2015; Accepted date: December 20, 2015; Published date: December 23, 2015

Copyright: ( 2015 Alzuwayed, et al. This is an open-access article distributed under the terms of the Creative Commons Attribution License, which permits unrestricted use, distribution and reproduction in any medium, provided the original author and source are credited.

\begin{abstract}
Introduction: Post-tonsillectomy bleeding remains the most serious complication of tonsillectomy. The rate of post tonsillectomy bleeding varies with different technique. The common used techniques are the bipolar, monopolar and cold.

Methods: This was a retrospective case series study based on chart review of children under 14 years who underwent tonsillectomy during the period between January 2010 to December 2011 at King Abdulaziz Medical City (KAMC), Riyadh, Saudi Arabia - ENT department. The charts of all the patients were reviewed by the student and the data form filled for included patients for the age, gender, indications for tonsillectomy, previous surgery, medications, admission type, technique used which are the bipolar, monopolar and cold technique and complications.
\end{abstract}

Results: Out of 60 patients reviewed, post tonsillectomy bleeding was reported in 16 (27\%). Indications for tonsillectomy were six indications and most common one was recurrent adenotonsillitis in 27 (46\%).

Intraoprative bleeding was 8 cases $(13 \%)$ which was the most common type of bleeding and there was no significant difference in post tonsillectomy bleeding between the three techniques $(p=0.62)$.

Conclusion: The result showed that there was no significant difference in post tonsillectomy bleeding between the three techniques.

Keywords: Post-tonsillectomy; Tonsils; Tonsillar hypertrophy

\section{Introduction}

The tonsils are tissue mass at the back of the throat. If they keep becoming infected, or if they enlarged and cause problems such as shortness of breath (SOB), they may need to be removed in an operation called tonsillectomy $[1,2]$. The indications for operation included chronic or recurrent tonsillitis three times or more in each of the three preceding years despite adequate medical therapy and tonsillar hypertrophy associated with positive history of snoring and restless sleep $[2,3]$.

Tonsillectomy is one of the most common surgical operations performed in the world, it is estimated to be more than 530,000 operations performed annually in children younger than $15[2,4]$. Post tonsillectomy bleeding remains the most serious complication of tonsillectomy [5]. The rate of post tonsillectomy bleeding varies with different technique [6]. Bleeding has been divided into two categories; primary, occurring less than 24 hour after surgery and secondary, occurring more than 24 hour, commonly 5-10 days after the operation. Secondary hemorrhage has a reported rate of 3-5\% leading to re-admission to hospital $[7,8]$.

Primary bleeding is generally considered to be related to surgical technique. Different techniques causing different rate of bleeding, systemic steroid can effect posttonsillectomy bleeding, environmental factors play a role in delaying healing process in secondary bleeding $[7,9,10]$.

In monopolar microdissection tonsillectomy removal of the tonsils was through subcapsular dissection using Colorado needle tip (Stryker-Leibinger, Freiburg, Germany), in the bipolar uses a combination of power, waveform, frequency, electrode size and time of application to produce a tissue temperature that will result in predictable histological effect and In the cold dissection tonsillectomy removal of both tonsils was by using cold surgical instruments and hemostasis secured by the bipolar diathermy.

This study will compare the incidence of post tonsillectomy bleeding between the three techniques that performed at NGHA (bipolar, monopolar, cold technique) to find the least post tonsillectomy bleeding incidence [11].

\section{Objectives of the Study}

\section{Aim of the study}

To find the least post tonsillectomy bleeding between the three techniques the bipolar, monopolar and cold technique in children younger than 14 years to reduce the risk of post-tonsillectomy bleeding rate. 
Citation: Alzuwayed A, Qattan M (2015) Comparison between Post-tonsillectomy Bleeding of Three Different Techniques in Children. Trop Med

Page 2 of 4

\section{Specific objectives}

To compare the rate of post tonsillectomy bleeding between different techniques.

\section{Methods}

A retrospective case-series study in which a chart review performed on children under 14 years who underwent tonsillectomy during the period between January 2010 to December 2011.

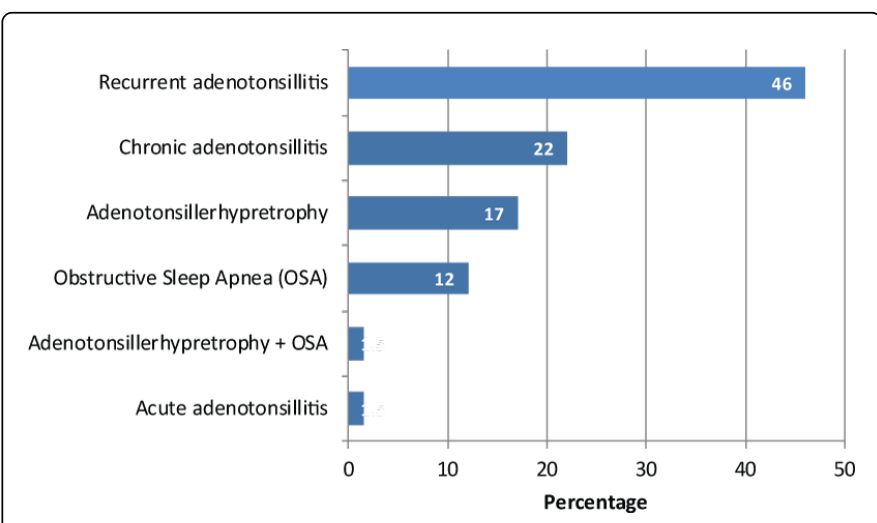

Chart 1: Indications for Tonsillectomy.

The charts of all the patients were reviewed by the student and the data form filled for included patients for the age, gender, indications for tonsillectomy, previous surgery, medications, admission type, technique used which are the bipolar, monopolar and cold technique and complications (Charts 1-3).

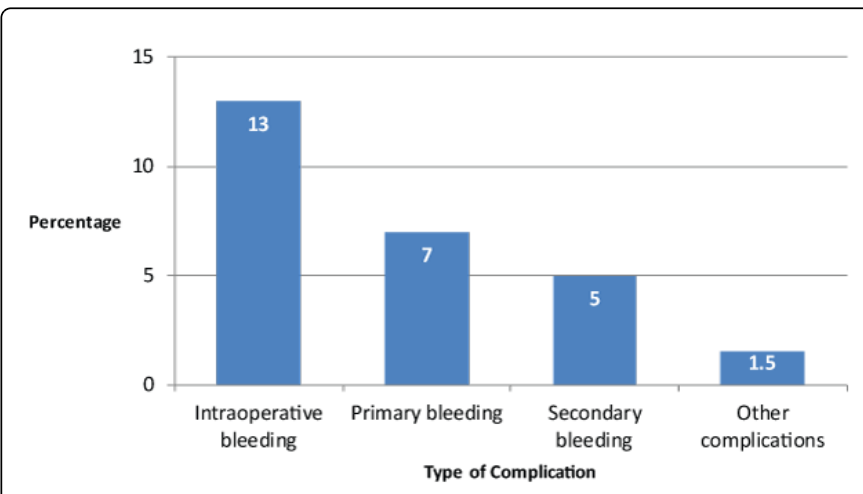

Chart 2: Types of Complications of Post-Tonsillectomy.

\section{Study area}

The study conducted in King Abdulaziz Medical City (KAMC), Riyadh, Saudi Arabia - ENT department; There are 600 tonsillectomy operated per year.

\section{Study subjects}

\section{Including criteria}

1- Children 14 years old or younger.

2- Tonsillectomy done at KFNGH during the period January 2010 and December 2011.

3- Adequate medical record data.

4- Minimal one week follow up after surgery.

\section{Exclusion criteria}

1- patient with coagulopathy.

2- patient taking anticoagulant.

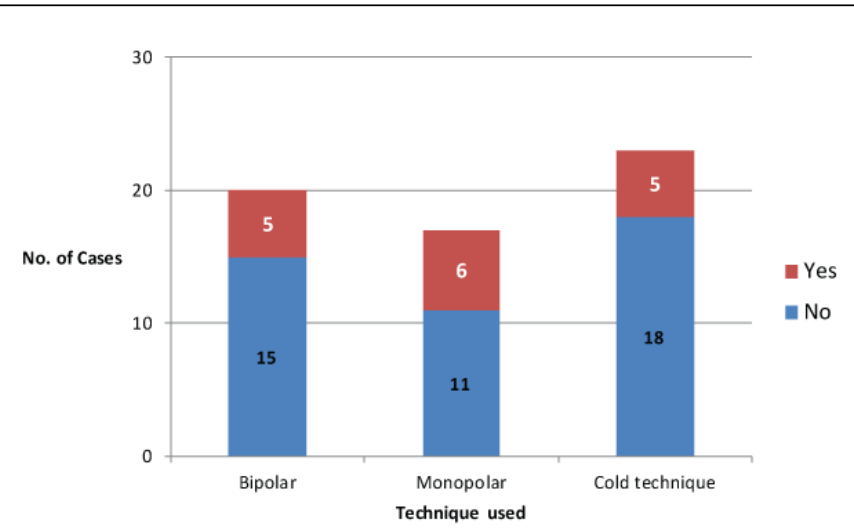

Chart 3: Proportion of Bleeding by Technique used for Tonsillectomy.

\section{Study design}

Retrospective case-series.

\section{Sample size}

All patients who underwent tonsillectomy at KFNGH between January 2010 and December 2011 and after doing the sample size calculation of $90 \%$ confidence level and 5\% margin of error to get least sample size that result in 97 patients but I had only 60 patients because of incomplete information in some files.

\section{Sampling technique}

This is a retrospective study of all patients who underwent tonsillectomy at KFNGH between January 2010 and December 2011 according to the inclusion and exclusion criteria. The chart of all patients reviewed by the student and the data form filled for included patients.

\section{Data collection methods, Instrument used, Measurements}

Through the Medical Record Department, the chart of all patients reviewed by the student according to the inclusion and exclusion criteria and the data form filled for included patients. 
Page 3 of 4

\section{Data management and analysis plan}

The study group divided into three groups:

Group one: patients who underwent tonsillectomy with cold technique.

Group two: patients who underwent tonsillectomy with bipolar electrocautery technique.

Group three: patients who underwent tonsillectomy with monopolar electrocautery technique.

Then we took from each patient the indications for the surgery, the type of admission, medications and past medical history.

After that we record for each surgery if there is bleeding or not and the type of bleeding.

(In each group data regarding age, sex, post-operative bleeding had been taken)

${ }^{*}$ Descriptive statistical presented as frequency and percentage.

Then we compared the incidence of bleeding between the three groups using Chi-squared test and SPSS statistical package.

\section{Ethical considerations}

The name and medical record number was not entered in the software, but had only accessible to the principal and CO-investigators.

\section{Results}

Sixty cases of tonsillectomy from different gender and age under 14 years were reviewed, the male gender was the majority of the sample $40(67 \%)$, the ages were between one year to six years, Clinical indications for operation were six and the most common one is the recurrent adenotonsillitis with $27(46 \%)$ cases, the majority of the cases were done as case day surgery 50 (83\%) (Table 1), for the techniques used, the Bipolar in 20 cases, Monopolar in 17 cases and the cold technique in 23 cases (Table 2).

The study results with analysis of all patients who underwent tonsillectomy at King Fahad National Guard between January 2010 and December 2011 that there were $16(26.7 \%)$ cases of posttonsillectomy bleeding and the most type of bleeding was intraoperative bleeding with eight cases, primary bleeding was four cases and secondary bleeding was three cases.

For the techniques which one causing bleeding, the monopolar was six cases, the cold technique and the bipolar were five for each (Table $3)$.

At the end our study didn't find significant difference in posttonsillectomy bleeding between the three techniques $(\mathrm{P}=0.62)$.

\begin{tabular}{|l|l|l|}
\hline & $\mathbf{N}=\mathbf{6 0}$ & $\%$ \\
\hline Sex & & \\
\hline Male & 40 & 67 \\
\hline Female & 20 & 33 \\
\hline
\end{tabular}

\begin{tabular}{|c|c|c|}
\hline Age (years) & & \\
\hline 1 & 14 & 23.5 \\
\hline 2 & 30 & 50 \\
\hline 5 & 1 & 1.5 \\
\hline 6 & 15 & 25 \\
\hline \multicolumn{3}{|l|}{ Indication } \\
\hline Adenotonsiller hypretrophy & 11 & 18 \\
\hline OSA & 8 & 13 \\
\hline Chronic adenotonsillitis & 13 & 22 \\
\hline Recurrent adenotonsillitis & 27 & 46 \\
\hline Acute adenotonsillitis & 1 & 1.5 \\
\hline \multicolumn{3}{|l|}{ Previous medical history* } \\
\hline Obstructive sleep apnea & 8 & 13 \\
\hline Bronchial asthma & 12 & 20 \\
\hline Snoring & 3 & 5 \\
\hline Otitiis media & 1 & 1.5 \\
\hline Seizure & 1 & 1.5 \\
\hline \multicolumn{3}{|l|}{ Previous surgery ${ }^{*}$} \\
\hline Probing & 1 & 1.5 \\
\hline Adenoidectomy & 1 & 1.5 \\
\hline \multicolumn{3}{|l|}{ Medication ${ }^{*}$} \\
\hline Ventolin & 11 & 18 \\
\hline Hydrocortison & 1 & 1.5 \\
\hline Ventolin + Sertide & 1 & 1.5 \\
\hline Ventolin + Flexotide & 2 & 3 \\
\hline \multicolumn{3}{|l|}{ Allergy } \\
\hline No known allergy & 56 & 94 \\
\hline Peanuts & 1 & 1.5 \\
\hline Egg & 2 & 3 \\
\hline Cefroxine & 1 & 1.5 \\
\hline \multicolumn{3}{|l|}{ Admission / Case day } \\
\hline Admission & 10 & 17 \\
\hline Day case & 50 & 83 \\
\hline \multicolumn{3}{|l|}{ Technique used } \\
\hline Bipolar & 20 & 33 \\
\hline Monopolar & 17 & 28 \\
\hline Cold technique & 23 & 38 \\
\hline
\end{tabular}

Table 1: Study performed under different conditions. 
Page 4 of 4

${ }^{*}$ Only positive cases reported - Missing are Not Applicable.

\begin{tabular}{|l|l|l|l|}
\hline \multirow{2}{*}{ Technique used } & \multicolumn{2}{|l|}{ Complications } & Total \\
\hline \multirow{3}{*}{ Bipolar } & No & Yes & \\
\hline \multirow{2}{*}{ Monopolar } & 15 & 5 & 20 \\
\cline { 2 - 4 } & $75 \%$ & $25 \%$ & $100 \%$ \\
\hline \multirow{2}{*}{ Cold technique } & 11 & 6 & 17 \\
\cline { 2 - 4 } & $65 \%$ & $35 \%$ & $100 \%$ \\
\hline \multirow{2}{*}{ Total } & 18 & 5 & 23 \\
\cline { 2 - 4 } & $78 \%$ & $22 \%$ & $100 \%$ \\
\hline $\mathbf{p = 0 . 6 2}$ & 44 & 16 & 60 \\
\cline { 2 - 4 } & $73 \%$ & $27 \%$ & $100 \%$ \\
\hline
\end{tabular}

Table 2: Number of complications for each technique.

${ }^{*}$ Complications include any type of bleeding and other complications.

\begin{tabular}{|l|l|l|}
\hline Intraoperative bleeding & $\mathbf{N}=\mathbf{6 0}$ & $\%$ \\
\hline No & 52 & 87 \\
\hline Yes & 8 & 13 \\
\hline Primary bleeding & & \\
\hline No & 56 & 93 \\
\hline Yes & 4 & 7 \\
\hline Secondary bleeding & & \\
\hline No & 57 & 95 \\
\hline Yes & 3 & 5 \\
\hline Other complications & & \\
\hline No & 59 & 98.5 \\
\hline Yes & 1 & 1.5 \\
\hline Any complications & & \\
\hline No & 44 & 73 \\
\hline Yes & 16 & 27 \\
\hline
\end{tabular}

Table 3: Number of each type of complications.

\section{Discussion}

Post-tonsillectomy hemorrhage remains the most serious complication of tonsillectomy. In comparing with the more recent systematic literature review identified a difference in the rate of posttonsilliectomy bleeding after different techniques for tonsilliectomy.

Post-tonsillectomy bleeding among children undergoing traditional tonsillectomy with those undergoing electrodessiction tonsillectomy were compared. A total of 190 children (2-12 years old). Eighty-Nine males and 101 females, who were admitted to Al-Namas General Hospital during the period of 2008 to 2011 for tonsillectomy were randomized into either traditional tonsillectomy (97 patients) or electrodissection tonsillectomy (93 patients). Postoperative hemorrhage was experienced by 6 cases who underwent traditional tonsillectomy (6.2\%) and 2 cases who underwent tonsillectomy by electrodissection (2.2\%). Difference between both study groups regarding postoperative hemorrhage was not statistically significant.

In other study in 2007, Australian a prospective institutional study for if there is different rate of post-tonsillectomy bleeding between the commonly used techniques, with one thousand one hundred thirtythree consecutive cases were analyzed the primary post-tonsillectomy hemorrhage rate was $0.2 \%$ for blunt dissection plus diathermy hemostasis and $0.3 \%$ for monopolar diathermy dissection plus hemostasis. Monopolar diathermy had a lower rate of secondary postoperative hemorrhage. These differences, however, did not reach statistical significance, and neither did the relative risk between the two techniques. Two-way analysis of variance among secondary posttonsillectomy hemorrhage complications by technique and by age groups shows a highly statistically significant difference by age group.

\section{Conclusion}

Since the study didn't find any significant difference in posttonsillectomy bleeding between the three techniques, our recommendation is to increase the sample size.

\section{References}

1. British Association of Otorhinolaryngologists. Electrosurgery (diathermy and coblation) for tonsillectomy. The National Institute for Health and Clinical Excellence (NICE). 14 December 2005; IPG150 [about 12 pages].

2. Baugh RF, Archer SM, Mitchell RB, Rosenfeld RM, Amin R, et al. (2011) Clinical practice guideline: tonsillectomy in children. Otolaryngol Head Neck Surg 144: S1-30.

3. Kamal J (2002) Tonsillectomy in Saudi Arabia. Bahrain Med B 24(2): 69-72.

4. Glover JA (2008) The incidence of tonsillectomy in school children. 1938. Int J Epidemiol 37: 9-19.

5. Iqbal Z, Rabbani MZ, Zafar MJ (2009) Post tonsillectomy hemorrhage incidence, a comparison between dissection and bipolar diathermy techniques. Rawal Med J 34: 23-5.

6. Ali RB, Smyth D, Kane R, Donnelly M (2008) Post-tonsillectomy bleeding: a regional hospital experience. Ir J Med Sci 177: 297-301.

7. Faramarzi A, Heydari ST (2010) Prevalence of Post-tonsillectomy Bleeding as Day-case Surgery with Combination Method; Cold Dissection Tonsillectomy and Bipolar Diathermy Hemostasis. Iran J Pediatr 20: 187-192.

8. Conley SF, Ellison MD (1999) Avoidance of primary post-tonsillectomy hemorrhage in a teaching program. Arch Otolaryngol Head Neck Surg 125: 330-333.

9. Levin B, Sacks R (2007) Post-tonsillectomy bleeding. Otolaryngol Head Neck Surg 136: S56-58.

10. Plante J, Turgeon AF, Zarychanski R, Lauzier F, Vigneault L, Moore L, et al. (2012) Effect of systemic steroids on post-tonsillectomy bleeding and reinterventions: systematic review and meta-analysis of randomised controlled trials. BMJ. [Meta-Analysis Research Support, Non-U.S. Gov't] 345: e5389.

11. Al-Shehri A (2012) Post-tonsillectomy pain and bleeding in children: A comparison of traditional tonsillectomy with electrodissection tonsillectomy. Cur Pediat Res 16: 150. 